\title{
Cabbage or 'pesticide' on the platter? Chemical analysis reveals multiple and excessive residues in African vegetable markets
}

\author{
Honest Machekano ${ }^{1,2}$, Wellington Masamba ${ }^{3}$, Brighton M. Mvumi² and Casper Nyamukondiwa ${ }^{1 *}$ (D)
}

\begin{abstract}
Overuse of pesticides in vegetables and related fresh products raises serious public health concerns. However, the recognition and assessment of the magnitude of public health risk remains a low priority in low income African communities. Brassicas are a cosmopolitan crop in African horticulture, and equally so, is the major economic pest, the diamondback moth, Plutella xylostella (L.). In consequence, insecticide use on P. xylostella in brassica production systems presents persistent pesticide overuse on produce directly destined for public consumption. Using the quick easy cheap effective rugged and safe (QuEChERS) multi-residue analysis method, followed by gas chromatographymass spectrometry (GC-MS) or liquid chromatography-tandem mass spectrometry (LC-MS/MS), we investigated the occurrence and magnitude of pesticide residues at three vegetable market levels (farmgates, vendors and supermarkets) in Botswana. We detected pesticide residues in $74.1 \%$ of the samples while $33.4 \%$ had multiple compounds. Farmgates recorded higher pesticide residues than other markets. We multi-detected 10 low-highly hazardous pesticides World Health Organisation (WHO)] (classes 1B \& II), that included Organophosphates, Pyrethroids, Neonicotinoids and Carbamates. Fifty percent of the detected pesticides from farms and supermarkets had residue quantities exceeding the Codex Maximum Residue Limit thresholds; although estimated daily per capita consumption was lower than the WHO Average Daily Intake (ADI) and Acute Reference Doses (ARfDs). These results indicate presence of multiple and excessive pesticide residues in routinely consumed vegetables on the markets, and points to an imminent public health hazard. Urgent attention is needed to develop and enforce effective policies and regulations on pesticide use practices and investment in non-chemical pest management alternatives.
\end{abstract}

Keywords: Pesticide residues, Brassica, Public health risk, Codex Alimentarius Maximum Residue Limits, Diamondback moth

\section{Introduction}

Sustainable agriculture under rapidly changing climate (IPCC 2014) and increasing human population (FAO 2009) remains a big challenge in Africa. However, it remains critical that food and nutrition challenges be addressed using sustainable approaches. For the horticultural industry, changes in temperature associated with climate change have created increased pest pressure

\footnotetext{
* Correspondence: nyamukondiwac@biust.ac.bw

${ }^{1}$ Department of Biological Sciences and Biotechnology, Botswana International University of Science and Technology, Private Bag 16, Palapye, Botswana

Full list of author information is available at the end of the article
}

(Newton et al. 2011) and pesticide overuse (Machekano et al. 2017, 2019) in an effort to increase crop productivity and profitability. This malpractice has resulted in production of pesticide laden agricultural produce, with negative implications on food safety and public health (Donkor et al. 2016). While human exposure to pesticide residues can be through different modes (Semple 2005), contaminated food remains the main exposure route (about five orders higher) (Nougadère et al. 2012; Szpyrka et al. 2015, reviewed in Donkor et al. 2016; Mebdoua et al. 2017). In brassicas, pesticide overuse is mainly associated with the high and stigmatic pesticide resistance history of the diamondback moth, Plutella 
xylostella (L.) (Lepidoptera: Plutellidae) (Furlong et al. 2013; Machekano et al. 2017). This is further aggravated by vegetables being consumed fresh as salads or partially processed e.g. cauliflower and cabbages (Mwanja et al. 2017) with no rigorous cooking process that could potentially degrade pesticide compounds. In addition, brassicas have been reported to capture more chemical content during direct spray and drift because of their large leaf surface area (Alla et al. 2015).

With the growing global health concerns on meat and related products, there is an increasing demand for vegetables because of their health benefits and affordability (see FAO 2004; Donkor et al. 2016). This has made brassica crops gain popularity in developing countries (Madisa et al. 2010; Mazhawidza and Mvumi 2017), making them a significant daily dietary component due to their richness in vitamins, minerals, fibre and antioxidants (FAO 2004). Simultaneously however, brassicas have become a major source of public health risk due to high incidence of pesticides residues (Szpyrka et al. 2015; Donkor et al. 2016; Jallow et al. 2017) associated with pesticide abuse (Ngowi et al. 2007; Machekano et al. 2019). In the drive to sustain food production in Africa, the use of insecticides in horticultural production systems is indispensable (Bhanti et al. 2004; Obopile et al. 2008; Williamson et al. 2008; Madisa et al. 2010). In Botswana for example, farmers are increasing the use of synthetic pesticides (Obopile et al. 2008; Machekano et al. 2019) to sustain horticultural yields and cope with increased demand for brassicas caused by increasing rural to urban migration (Madisa et al. 2010).

In a survey recently conducted in Botswana, $P$. xylostella accounted for the need to apply pesticides on brassica crops in $71.6 \%$ of the cases (Machekano et al. 2019). Forty one moderate to highly hazardous insecticide active ingredients (see WHO, 2009) targeted on $P$. xylostella control alone were recorded; some applied as pesticide 'cocktails' of more than two pesticides to respond to P. xylostella high pest pressure (Machekano et al. 2019). High residues may be exacerbated by the application of these pesticides too close to harvesting time without due consideration for the recommended withdrawal periods because of market competition and the need to protect a clean supply reputation. Farmers may sell their brassica crops before recommended withdrawal periods; a practice that then exposes the unsuspecting public to pesticide-contaminated food. Moreover, in developing countries, consumers purchase directly from farm-gates, apart from vendors and retailers (Madisa et al. 2010); all devoid of means to detect and quantify pesticide residues on the produce. The indiscriminate application of different types and quantities of pesticides on vegetables calls for an urgent need for evaluation of the magnitude of the public health risk. The main focus of many horticultural farmers in most African countries is skewed towards increasing quantity and not safety of the produce (Leroy et al. 2015). In addition, the technical sophistication of residue analysis makes the regulation, enforcement and compliance with the WHO/FAO Maximum Residue Limits (MRLs) under the Codex Alimentarius standards a big challenge at each level of the value chain to most developing countries (Amoah et al. 2006; Damallas and Eleftherohorinos 2011; Mwanja et al. 2017).

Studies carried out to date were mostly focused on occupational exposure (Magauzi et al. 2011; Hinson et al. 2017), neglecting the vulnerable passive exposure to consumers (Repetto and Baliga 1996; Semple 2005) through consumption of chemical residues on consumer-ready 'fresh' vegetable products procured from the markets (Nougadère et al. 2012). Generally, quantifying pesticide exposure is currently the quickest way of assessing and quantifying the risk of public exposure to pesticides in Africa (Semple 2005). Direct acute or chronic health effects are difficult to measure due to chemical interactive or dose-addition effects caused by continuous consumption of multiple chemicals in different products that then mar diagnostic accuracy especially in ill-equipped developing countries' laboratories (Ngowi et al. 2007; Boobis et al. 2008; Macharia et al. 2015). In addition, there are synergistic complexities associated with multiple pesticide toxicity, mycotoxicity and interaction with existing chronic illnesses (e.g. HIV and AIDS) that further obfuscates recognition and quantification of pesticide exposure risks (Repetto and Baliga 1996; Mostafalou and Abdollahi 2013). Therefore, methodologies to assess public health risks from exposure to multiple residues simultaneously, including their possible chemical interactive effects within the human body are currently lacking, especially under African contexts (Ngowi et al. 2007; Boobis et al. 2008; Macharia et al. 2015). Since policy enforcement (Damallas and Eleftherohorinos 2011) and public awareness may be the most effective way to minimize the problem through enforcing farmers' behavioural change (Williamson et al., 2008), there is urgent need to generate convincing evidence for policymakers on the nature and magnitude of the problem and the associated potential health threats (e.g. cholinergic syndrome (Fulco et al. 2000), different types of cancers, cardiovascular diseases (CVDs), birth defects, reproductive disorders and Parkinson's disease (Mostafalou and Abdollahi 2013)). Chemical analysis of fresh produce on the market for detection and quantification of pesticide residues therefore, brings warning evidence that can be used as early warning system by policymakers to take measures that will protect public health.

In Botswana, and indeed other developing countries, pesticide related health issues constitute a serious threat to 
development (Ngowi et al. 2007; Macharia et al. 2015; Jallow et al. 2017), yet, data on public health risk assessment, detection and quantification of potentially harmful pesticide residues in vegetables or related products remain scarce. Cognizant of the uncontrolled injudicious use of pesticides against $P$. xylostella (see details in Machekano et al. 2019) and using cabbages as a case study, we hypothesize that chemical residues are present on consumer-ready-cabbages at all three types of dominant domestic vegetable markets in Botswana. We further hypothesise that the quantities of pesticide residues may exceed the permissible Codex Alimentarius MRLs. The objective of this study was therefore to detect, characterize and quantify potential pesticide residues in fresh African cabbage markets using Botswana as a sampling point. This information is critical in advising policy-makers, pesticide regulators, consumers and farmers alike on the potential health risks associated with exposure to high levels of toxic chemical residues in fresh produce and the urgent need for respective remedial action.

\section{Methods}

\section{Sample collection and preparation}

Cabbage samples were collected from three high brassica production districts of Botswana vis Central; North East and South East districts (Table 1). All samples were procured under normal consumer-ready-purchasing-conditions to take into account realistic consumer (public) exposure conditions and to reduce bias (Nougadère et al. 2012; Mwanja et al. 2017). Sampling was done from a three-tier market system (vendors, supermarkets and farms), to cater for all types of markets used by vegetable consumers under an African context (see Osei-Fosu et al. 2017). At each sampling point, peripheral data such as the Global Positioning System (GPS) coordinates, the name of the sampling point (vendor, supermarket or farm) as well as the dates when the sampled consignment was delivered to the retailer (in the case of vendors or supermarkets) were recorded. Sampling was done following standardized random sampling methods (Fernandez-Alba 2005; Amoah et al. 2006; Bempah et al. 2011; Osei-Fosu et al. 2017; Mwanja et al. 2017).

Most vendors kept their stock on tables or at the back of trucks/vans. After normal purchasing process, nine whole cabbage heads were randomly picked from a vendor's table, truck or van. The process was repeated three times in each district (3 vendors) to yield three vendor replicates for each district (Table 1). The same process was repeated for the supermarkets (Fernandez-Alba 2005; Amoah et al. 2006). At farm level, only farm-fields that had physiologically mature cabbages that were already being harvested for marketing were sampled. Three whole cabbage heads were randomly picked from each cabbage row by picking every 10th cabbage within a row from a random starting point. Three or five lines were skipped (depending on the size of the field) and the process was repeated until a compound sample of nine cabbages was obtained. Sampled plot sizes ranged roughly from $0.3-0.6$ ha typical of small scale farmers' acreage in Botswana. The farm field sampling was based on the notion that when consumers are purchasing from farms, the cabbages are immediately harvested from the field following payment. To avoid field edge bias, the first three rows on either side of the field and the first 10 cabbage heads within a row were discarded.

From each of the compound sample of whole cabbage heads, 4 equidistant slices were cut from the surface to the core of each cabbage head and pulled out (synonymous of 'cake slice') using a laboratory knife. These were further sliced into small pieces and mixed in $45 \times 35 \mathrm{~cm}$ laboratory trays to obtain a sliced composite sample (see Mwanja et al. 2017). A $1 \mathrm{~kg}$ subsample was then measured out using a laboratory balance (RADWAG Wagi Elektronikczne, Model PS 4500.R2, Poland) and placed into sterile $44 \times 30 \mathrm{~cm}$ ziploc bags which were immediately sealed and placed on ice in a laboratory cooler box maintained at about $0 \pm 1{ }^{\circ} \mathrm{C}$. The trays were washed and lined with new plastic ( $>100 \mu \mathrm{m}$ thick) before preparing the next sample to avoid contamination.

\section{Sample preparation}

Samples were prepared using the quick easy cheap effective rugged and safe QuEChERS method (Anastasiades et al. 2003). Briefly, samples were processed using Foss food cutter and homogenized (Ultra Turrax T25). Thereafter $10 \mathrm{~g}$ of each homogenate was placed in 50 $\mathrm{mL}$ polypropylene tubes with screw caps. The extraction solvent acetonitrile was then added to each subsample and shaken for $1 \mathrm{~min}$ until uniform. Buffering citrate salts and sodium chloride ( $\mathrm{pH} 5-5.5)$, were also added and the mixture shaken intensively for $1 \mathrm{~min}$ followed by centrifugation at $5000 \mathrm{rpm}$ to allow for phase separation. The organic phase was thereafter cleaned-up using the dispersive solid phase extraction (d-SPE) method. Briefly, $1 \mathrm{ml}$ of the supernatant of the subsample was transferred into a new $2 \mathrm{ml}$ centrifuge tube containing primary and secondary amine (PSA) and magnesium sulphate. PSA was added for the removal of sugar, fatty acids and organic acids, while magnesium sulphate was used as a drying agent; to remove any residual water see also (Paya et al. 2007). Finally the mixtures were shaken followed by centrifugation to produce clear supernatant for GC-MS and LC-MS/MS analysis as required (Table 2).

\section{Stock and standards solutions preparations}

All solvents, namely acetonitrile, methanol and water were of HPLC grade. A single composite working standard solution at $100 \mu \mathrm{g} / \mathrm{mL}$ was prepared in methanol 
Table 1 Summary details of the sampling sites, including the type of sampling market, district, village and geographic positioning of the site

\begin{tabular}{|c|c|c|c|c|}
\hline Type of market & Sample code ${ }^{a}$ & District & Village/Mall/Town & GPS Coordinates \\
\hline Supermarket & NEsup $_{1}$ & North East & Sunshine Plaza mall & S21. 11,115, E027. 32,117 \\
\hline Supermarket & NEsup $_{2}$ & North East & Nzano Centre Mall & S21. 10,697, E027. 30,700 \\
\hline Supermarket & $\mathrm{NEsup}_{3}$ & North East & Sunshine Plaza mall & S21. 11,115, E027. 32,117 \\
\hline Vendor & NEven $_{1}$ & North east & Francistown Block 6 & S21. 12,328, E027. 32,177 \\
\hline Vendor & NEven $_{2}$ & North East & Francistown bus rank & S21. 10,296, E027.30688 \\
\hline Vendor & NEven $_{3}$ & North East & Gallo Mall & S21. 10,391, E027. 30,883 \\
\hline Farm & NEfar $_{1}$ & North East & Ditladi & S21. 26,013, E027. 28,170 \\
\hline Farm & $\mathrm{NEfar}_{2}$ & North East & Gulushabe & S21. 28,718, E027. 31,533 \\
\hline Farm & $\mathrm{NEfar}_{3}$ & North East & Gulushabe & S21. 26,013, E027. 32,100 \\
\hline Supermarket & Csup $_{1}$ & Central & Palapye & S22. 33,336, E027. 07718 \\
\hline Supermarket & $\operatorname{Csup}_{2}$ & Central & Boiteko junction mall & S22. 25,261, E026. 44,709 \\
\hline Supermarket & $\mathrm{Csup}_{3}$ & Central & Mahalapye & S23. 06551, E026. 50,014 \\
\hline Vendor & Cven $_{1}$ & Central & Serorome ward & S22. 32,644, E027. 06175 \\
\hline Vendor & Cven $_{2}$ & Central & Mahalapye Bus rank & S23. 06672, E026. 49,973 \\
\hline Vendor & $\mathrm{Cven}_{3}$ & Central & Shoshong & S23. 01806, E026. 30,813 \\
\hline Farm & $\mathrm{Cfar}_{1}$ & Central & Serowe & S22. 26,013, E026. 44,709 \\
\hline Farm & $\mathrm{Cfar}_{2}$ & Central & Palapye & S22. 34,965, E027. 05266 \\
\hline Farm & $\mathrm{Cfar}_{3}$ & Central & Modiane village & S23. 06628, E026. 43,079 \\
\hline Supermarket & SEsup $_{1}$ & South East & Pakhalane & S24. 33,836, E025. 58,572 \\
\hline Supermarket & SEsup $_{2}$ & South East & Rail Park Mall & S24. 39,582, E025. 54,124 \\
\hline Supermarket & $\mathrm{SEsup}_{3}$ & South East & Riverwalk Mall & S24. 40,548, E025. 56,036 \\
\hline Vendor & SEven $_{1}$ & South East & Gaborone bus rank & S24. 39,516, E025. 54,137 \\
\hline Vendor & SEven $_{2}$ & South East & Gaborone West & S24. 39,575, E025. 54,047 \\
\hline Vendor & $\mathrm{SEven}_{3}$ & South East & Tlogatloga ward & S24. 39,089, E025. 53,259 \\
\hline Farm & SEfar $_{1}$ & South East & Glen Valley & S24. 36,864, E025. 58,149 \\
\hline Farm & $\mathrm{SEfar}_{2}$ & South East & Glen Valley & S24. 36,500, E025. 58,293 \\
\hline Farm & $\mathrm{SEfar}_{3}$ & South East & Glen Valley & S24. 36,256, E025. 58,574 \\
\hline
\end{tabular}

${ }^{a}$ NEven North East District vendor, NEsup North East district supermarket, NEfar North East district farm, Cven Central district vendor, Csup Central district supermarket, Cfar Central district farm, SEsup South East district supermarket, SEven South East district vendor, SEfar South East district farm; numbers 1, 2, 3 represent replications

and stored at $-20^{\circ} \mathrm{C}$. LC-MS/MS the stock solutions $\left(1 \times 10^{-3} \mathrm{~g} / \mathrm{mL}\right.$ or $\left.5 \times 10^{-4} \mathrm{~g} / \mathrm{mL}\right)$ of each of the single compounds were prepared in acetonitrile. Stock work dilution mixtures $\left(1 \times 10^{-5} \mathrm{~g} / \mathrm{mL}\right)$ were prepared in acetonitrile and kept for the preparation of the work dilutions. The following work dilutions were prepared: $\left(2 \times 10^{-6}, 1 \times 10^{-6}, 5 \times 10^{-7}, 3 \times 10^{-7}, 1 \times 10^{-7}, 5 \times 10^{-8}\right.$, $3 \times 10^{-8}, 2 \times 10^{-8}$ and $1 \times 10^{-8} \mathrm{~g} / \mathrm{mL}$ ) in acetonitrile. For GC-MS, stock solutions $\left(1 \times 10^{-3} \mathrm{~g} / \mathrm{mL}\right.$ or $5 \times 10^{-4} \mathrm{~g} /$ $\mathrm{mL}$ ) of each of the single compounds were prepared in toluene. Work dilution mixtures of $5 \times 10^{-5} \mathrm{~g} / \mathrm{mL}$ were prepared in toluene and kept for the preparation of the work dilutions. The following work dilutions were prepared: $\left(2 \times 10^{-6}, 1 \times 10^{-6}, 5 \times 10^{-7}, 3 \times 10^{-7}, 1 \times 10^{-7}\right.$, $5 \times 10^{-8}, \quad 3 \times 10^{-8}, \quad 2 \times 10^{-8}$ and $\left.1 \times 10^{-8} \mathrm{~g} / \mathrm{mL}\right)$ in hexane.

\section{LC-MS/MS analysis}

LC-MS/MS was run using the South African Bureau of Standards (SABS) inhouse method no. 029/2006 validated for the determination of pesticides in fruits and vegetables at concentration range of $0.01-1.0 \mathrm{mg} / \mathrm{kg}$ on LM-MS/MS with a limit of quantitation (LOQ) of 0.01 $\mathrm{mg} / \mathrm{kg}$. Summary of the validation data and compounds included are provided (Additional file 1: Table S1). $100 \mu \mathrm{L}$ of supernatant was injected into a Kinetex column (Phenomenex, United States) of particle sizes 150 $\mathrm{mm} \times 4.6 \mathrm{~mm}$. The mobile phase consisted of a mixture of high-purity water with $0.1 \%$ formic acid (A) and acetonitrile (B). In order to separate the ions, a gradient programme started with $90 \% \mathrm{~A}$ and $10 \% \mathrm{~B}$ for $2 \mathrm{~min}$, thereafter, there was a gradual change in mobile phase which took 26 min until 5\% A and 95\% B was reached. 
Table 2 Sample analysis techniques (GC-MS and LC-MS/MS) and limit of quantitation (LOQ) used to detect and quantify different types of pesticides in our experiments

\begin{tabular}{|c|c|c|c|}
\hline Pesticide & Pesticide group & Technique used & $\left(\mathrm{LOQ}^{\mathrm{a}}\right)(\mathrm{mg} / \mathrm{kg})$ \\
\hline Chlorpyriphos & Organophosphate & GC-MS & 0.01 \\
\hline Triazophos & Organophosphate & & 0.01 \\
\hline Cypermethrin & Pyrethroid & & 0.02 \\
\hline Fenvarelate & Pyrethroid & & 0.02 \\
\hline Chlorfenapyr & Pyrole & & 0.01 \\
\hline Acephate & Organophosphate & LC-MS/MS & 0.01 \\
\hline Methamidophos & Organophosphate & & 0.01 \\
\hline Methomyl & Carbamate & & 0.01 \\
\hline Chorantraniliprole & Diamide & & 0.01 \\
\hline Imidacloprid & Neonicotinoids & & 0.01 \\
\hline
\end{tabular}

a LOQ Limit of quantitation

Thereafter, the mobile phase was kept constant at 5.0\% A and $95 \%$ B for $32 \mathrm{~min}$, and finally, gradually increased back to $90 \% \mathrm{~A}$ and $10 \% \mathrm{~B}$ which took $38 \mathrm{~min}$. A tandem mass spectrometer (Agilent 6460, Germany) was used for detection using Mass Hunter ${ }^{\bullet}$ quantitation software (Agilent Technologies, United States).

\section{Gas chromatography mass spectrometry (GC-MS)}

The GC-MS was run using the South African Bureau of Standards (SABS) in-house method no. 029/2006 validated for the determination of organochlorines (OCs), organophosphates (OPs) and synthetic pyrethroids in fruits and vegetables at concentration range of $0.01-$ $0.05 \mathrm{mg} / \mathrm{kg}$ by GC-ECD and FPD with a limit of quantitation (LOQ) of $0.01 \mathrm{mg} / \mathrm{kg}$ for both OCs and OPs and $0.02 \mathrm{mg} / \mathrm{kg}$ for synthetic pyrethroids. Summary of the validation data and compounds included are provided (Additional file 1: Table S2). The analysis was performed with an Agilent technologies 6890 gas chromatography equipped with an inert mass selective detector (MSD), model 5975 (Agilent Technologies, USA). The system was operated in a splitless mode. The GC column was an Agilent J \&W GC column (model: Agilent 19091S-433, HP-5MS) of length $30 \mathrm{~m}$, internal diameter of $0.250 \mathrm{~mm}$ and film thickness of $0.25 \mu \mathrm{m}$. The column was kept at a constant flow rate of $0.9 \mathrm{ml} / \mathrm{min}$. Helium was used as the carrier gas. The inlet and detector temperatures were maintained at $250{ }^{\circ} \mathrm{C}$ and $325^{\circ} \mathrm{C}$ respectively. The temperature program started at an initial temperature of $80^{\circ} \mathrm{C}$ for $1 \mathrm{~min}$, followed by a gradient programme to an elution temperature of $325{ }^{\circ} \mathrm{C}$ for a total runtime of 38 min. The validation data for both GC-MS and LC-MS/MS are presented in electronic supplementary materal, Additional file: 1 .

\section{Data analysis}

Mass Hunter ${ }^{\bullet}$ quantitation software (Agilent Technologies, United States) was used for quantification. Data were analysed in STATISTICA 13.3 (TIBCO Software Inc. USA). Data that did not meet linear model assumptions of constant variance and normal errors were analysed using generalized linear models (GLZ) and Kruskal-Wallis post-hoc tests were used to separate statistically different medians. For multi-detected individual pesticides, the data satisfied the ANOVA assumptions, therefore, one-way ANOVA was used. Tukey-Kramers HSD test was used to separate statistically significant means. Linear regression analysis using 2D scatterplots was done in STATISTICA to assess the correlation between detected quantities and number of days after delivery. To measure the magnitude of public exposure, we calculated per capita residue consumption following Mwanja et al. (2017) only for the six detected highly hazardous pesticides that exceeded the Codex MRLs, and compared the figures to the recommended acceptable daily intake (ADI) and the acute reference doses (ARfD) for the individual pesticides based on recommended per capita consumption of leafy vegetables in Africa of $0.7 \mathrm{~g} /$ person/annum (WHO/GEMS/FOODS 2006) and $60 \mathrm{~kg}$ body weight $(\mathrm{BW})$ as in Alla et al. (2015).

\section{Results}

\section{Detections, identification and quantification}

Retention time (RT) and mass-to-charge ratio $(\mathrm{m} / \mathrm{z})$ were used to identify positive peaks for detected compounds in both GC-MS and LC-MS/MS analyses (Fig. 1). Figure 1a shows the LC-MS/MS multiple chromatograms for a sample from a vendor based at Shoshong (see details in Table 1). The graph shows positive peaks for methamidophos $(\mathrm{RT}=4.161 \mathrm{~min}$, concentration $=$ $0.0262 \mathrm{mg} / \mathrm{kg})$, methomyl $(\mathrm{RT}=10.163 \mathrm{~min}$, concentration $=0.0140 \mathrm{mg} / \mathrm{kg}), \quad$ chlorantraniliprole $\quad(\mathrm{RT}=20.282$ min, concentration $=0.0350 \mathrm{mg} / \mathrm{kg}$ ). All the other detected LC-MS/MS amenable compounds were identified in the same manner. The GC-MS chromatograms for a single detection for a sample from a supermarket in Gaborone are shown in Fig. 1b exemplified by chlorfenapyr $(\mathrm{RT}=20.269 \mathrm{~min}$, concentration $=0.5721 \mathrm{mg} / \mathrm{kg})$.

Pesticide residues were detected in $74.1 \%$ of the tested samples at all market levels, i.e. farms, vendors and supermarkets combined (Fig. 2a) across all the sampled districts (Fig. 2b). Samples from the farms showed higher $\mathrm{KW}-\mathrm{H}_{(2,34)}=10.255$, $(p=0.0059)$ detected quantities of pesticide residues than samples from both supermarkets and vendors (Fig. 2a). However, there were no significant differences $\left.\mathrm{KW}-\mathrm{H}_{(2,}, 34\right)=2.8411, \quad(p=$ $0.2416)$ in the quantity of pesticides detected across all sampled districts (Fig. 2b). Generally, the number of 


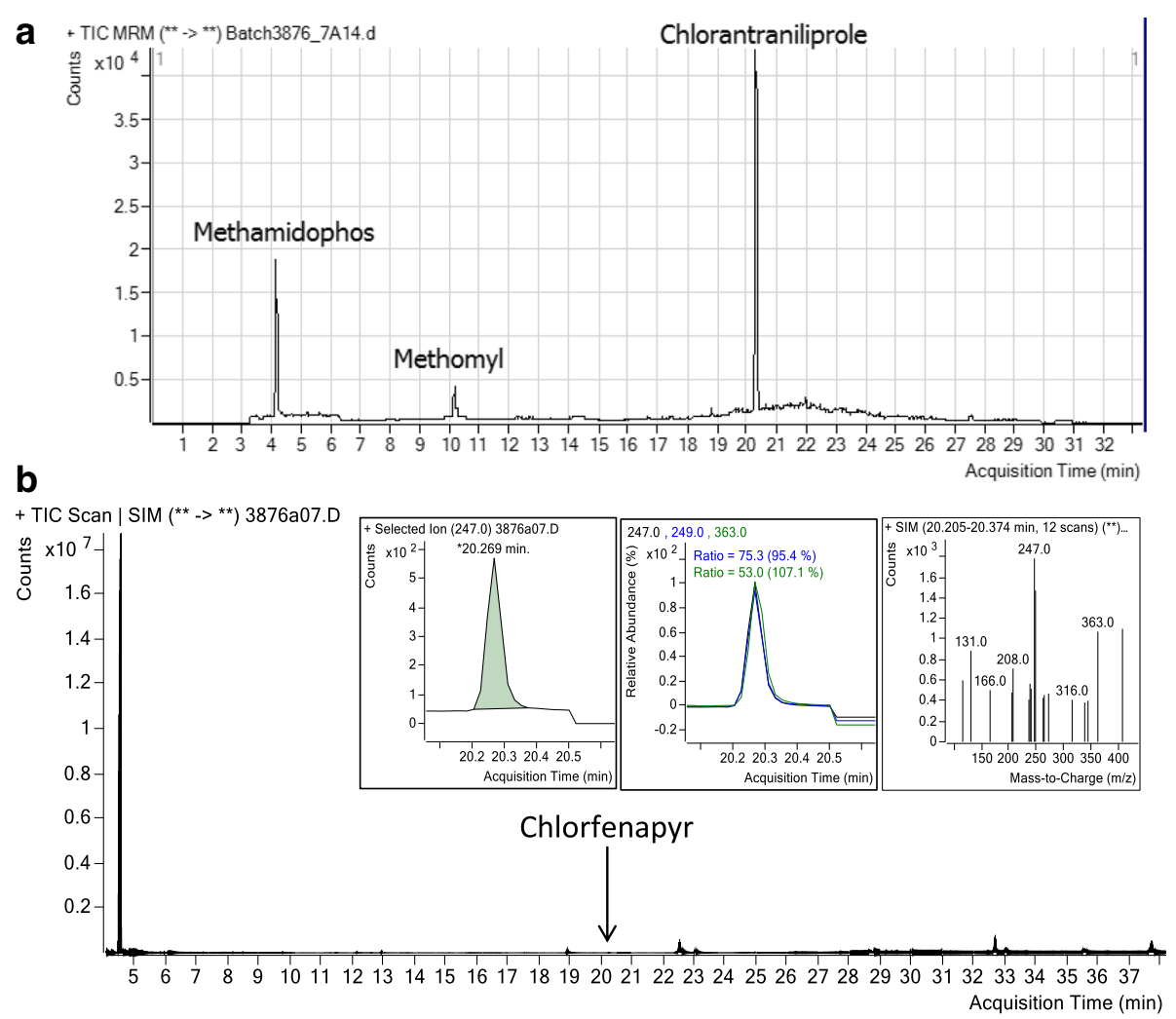

Fig. 1 Chromatograms for (a) LC-MS/MS showing peaks for 3 multi-detected pesticide residues for a sample from a vendor at Shoshong shopping centre in Central District (S23. 01806, E026. 30,813) (methamidophos: RT $=4.161 \mathrm{~min}$, concentration $=0.0262 \mathrm{mg} / \mathrm{kg} ; \mathrm{methomyl:} \mathrm{RT}=10.163$, concentration $=0.0140 \mathrm{mg} / \mathrm{kg}$ and chlorantraniliprole: RT $=20.282 \mathrm{~min}$, concentration $=0.0350 \mathrm{mg} / \mathrm{kg}$ ). $\mathbf{b}$ GC-MS showing peaks residues for chlorfenapyr (RT $=20.269 \mathrm{~min}$, concentration $=0.5271 \mathrm{mg} / \mathrm{kg}$ ) from a sample from a supermarket in South East District (S24.39582, E025. 54,124). The insertion in $1 \mathrm{~b}$ shows the extracted and zoomed GC-MS peaks and mass-to-charge ratios for Chlorfenapyr. (Batch 3876_7A14.d and 3876a07D represents laboratory sample coding. RT = Retention time in minutes)
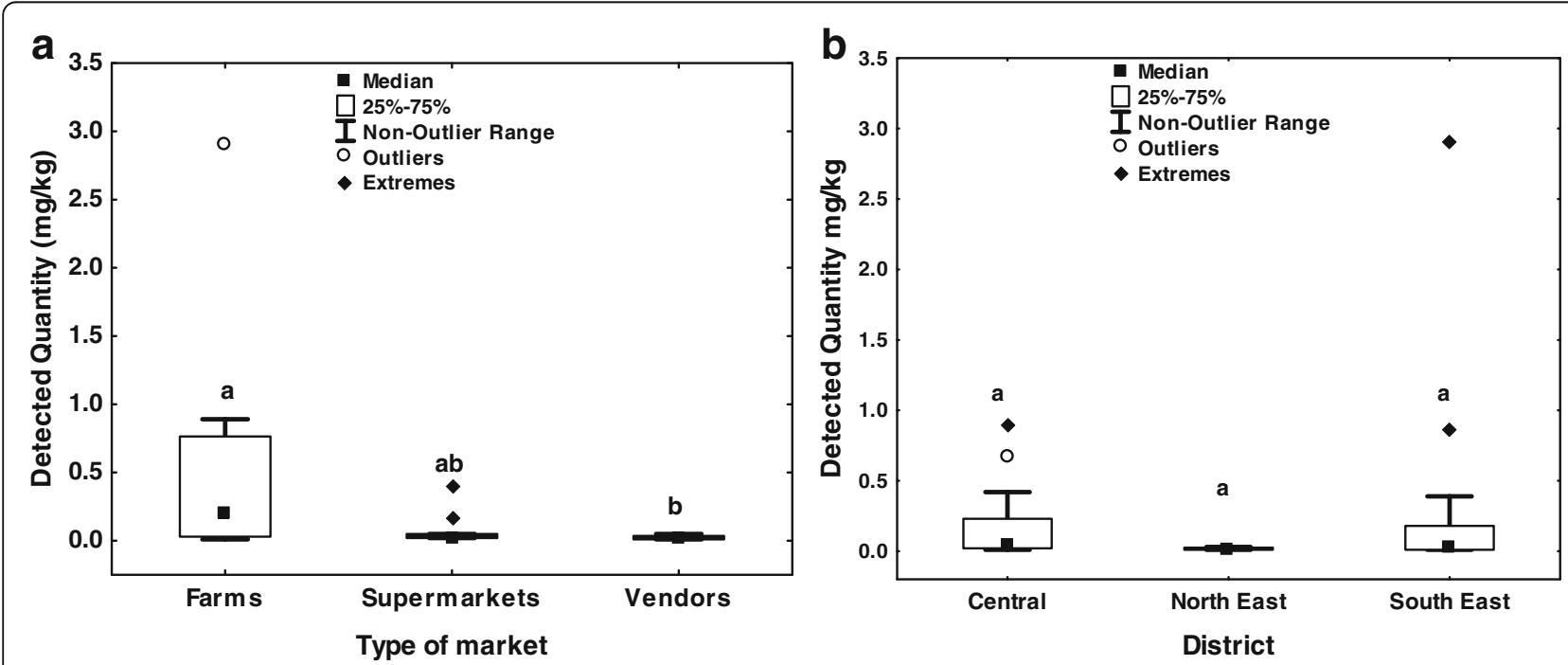

Fig. 2 Median $\pm 95 \%$ CLs of the detection of pesticide residues across (a) markets and (b) districts Kuskall-Wallis post-hoc tests were used to separate heterogenous groups at $P=0.05$. Group medians with the same letter(s) are not statistically different 
samples with pesticide residues (\% proportion of detections per type of market) were higher in the farms and supermarkets compared to vendors.

A total of ten different active ingredient residues were multi-detected from 27 cabbage samples including four organophosphates (methamidophos, triazophos, acephate and chlorpyriphos), two pyrethroids (cypermethrin and fenvarelate), one carbamate (methomyl), one pyrrole (chorfenapyr), one neonicotinoid (imidacloprid) and one diamide (chlorantraniliprole) (see Table 3). Methamidophos, triazophos and methomyl fall in hazard class $1 \mathrm{~B}$, classified as highly hazardous (WHO 2009). Methomyl and methamidophos were multi-detected across all types of markets in all sampled districts while triazophos was detected only from vendors in one district (North East) (Table 3). Six of the detected pesticides; cypermethrin, fenvarelate, acephate, chlorpyriphos, chlorfenapyr and imidacloprid belong to WHO toxicity class II, described as moderately hazardous (WHO 2009) (Table 3). The 'unlikely hazardous' (WHO 2009) chlorantraniliprole was detected 4 times across all types of markets in the
Central district only. For individual pesticides, overall proportion of detections was higher for methamidophos, followed by cypermethrin; methomyl and chlorantraniliprole (see Fig. 3a). Most of the samples included only one detectable pesticide, while at least two detected pesticides were found in $33.4 \%$ of the samples (Fig. 3b). The detected quantity of pesticides were negatively correlated $(\mathrm{r}=-0.269, p<0.001)$ to the length of time (number of days) between the vendor or supermarket's date of receiving supply and the time of sampling.

\section{Risk assessment}

A total of $50 \%$ (17/34) of total detections, dominated by organophosphates were above the Codex Alimentarius MRLs. Detected residue quantities for methomyl were significantly higher $(p<0.001)$ on samples from the farms $(0.67 \mathrm{mg} / \mathrm{kg})$ compared to supermarkets $(0.045$ $\mathrm{mg} / \mathrm{kg})$ and vendors $(0.01 \mathrm{mg} / \mathrm{kg})$. On the other hand, residues from supermarkets were significantly higher $(p$ $<0.001)$ than samples from vendors. Methomyl residues from both supermarkets and farms exceeded the FAO/

Table 3 Summary information on the detected insecticides, the pesticide classification group, its classification according to toxicity, the source (district and market type) of sampling and the number of times each compound was detected

\begin{tabular}{|c|c|c|c|c|c|c|c|}
\hline Pesticide & Pesticide Group & WHO Hazard class & Description & District & $\begin{array}{l}\text { Type of market } \\
\text { (sample source) }\end{array}$ & $\begin{array}{l}\text { No. of times } \\
\text { detected }\end{array}$ & $\begin{array}{l}\text { Total } \\
\text { detections }\end{array}$ \\
\hline \multirow[t]{3}{*}{ Methamidophos } & \multirow[t]{3}{*}{ Organophosphate } & \multirow[t]{3}{*}{$\mathrm{IB}$} & \multirow[t]{3}{*}{ Highly hazardous } & Central South East & $\begin{array}{l}\text { Farm } \\
\text { Farm }\end{array}$ & $\begin{array}{l}1 \\
3\end{array}$ & \multirow[t]{3}{*}{10} \\
\hline & & & & South East & Supermarkets & 2 & \\
\hline & & & & Central South East & $\begin{array}{l}\text { Vendor } \\
\text { Vendor }\end{array}$ & $\begin{array}{l}1 \\
3\end{array}$ & \\
\hline Triazophos & Organophosphate & $\mathrm{IB}$ & Highly hazardous & North East & Vendor & 1 & 1 \\
\hline \multirow[t]{3}{*}{ Methomyl } & \multirow[t]{3}{*}{ Carbamate } & \multirow[t]{3}{*}{$\mathrm{IB}$} & \multirow[t]{3}{*}{ Highly hazardous } & Central & Farm & 1 & \multirow[t]{3}{*}{5} \\
\hline & & & & Central & Supermarket & 2 & \\
\hline & & & & South East & Vendor & 2 & \\
\hline \multirow[t]{3}{*}{ Cypermethrin } & \multirow[t]{3}{*}{ Pyrethroid } & \multirow[t]{3}{*}{$\|$} & \multirow[t]{3}{*}{ Moderately hazardous } & Central & Farms & 1 & \multirow[t]{3}{*}{5} \\
\hline & & & & Central North East & $\begin{array}{l}\text { Supermarket } \\
\text { Supermarket }\end{array}$ & $\begin{array}{l}1 \\
1\end{array}$ & \\
\hline & & & & South East & Vendor & 2 & \\
\hline \multirow[t]{2}{*}{ Acephate } & \multirow[t]{2}{*}{ Organophosphate } & \multirow[t]{2}{*}{$\|$} & \multirow[t]{2}{*}{ Moderately hazardous } & Central & Farm & 2 & \multirow[t]{2}{*}{3} \\
\hline & & & & South East & Vendor & 1 & \\
\hline \multirow[t]{3}{*}{ Chlorfenapyr } & \multirow[t]{3}{*}{ Pyrrole } & \multirow[t]{3}{*}{$\|$} & \multirow[t]{3}{*}{ Moderately hazardous } & Central & Farm & 1 & \multirow[t]{3}{*}{3} \\
\hline & & & & South East & Supermarket & 1 & \\
\hline & & & & South East & Vendor & 1 & \\
\hline \multirow[t]{2}{*}{ Chlorpyrifos } & \multirow[t]{2}{*}{ Organophosphate } & \multirow[t]{2}{*}{$\|$} & \multirow[t]{2}{*}{ Moderately hazardous } & South East & Farm & 1 & \multirow[t]{2}{*}{2} \\
\hline & & & & Central & Supermarket & 1 & \\
\hline Fenvalerate & Pyrethroid & $\|$ & Moderately hazardous & North East & Supermarket & 1 & 1 \\
\hline Imidacloprid & Neonicotinoid & $\|$ & Moderately hazardous & North East & Vendor & 1 & 1 \\
\hline \multirow[t]{3}{*}{ Chlorantraniliprole } & \multirow[t]{3}{*}{ Anthranilic diamides } & \multirow[t]{3}{*}{$\mathrm{N} / \mathrm{A}$} & \multirow[t]{3}{*}{ Unlikely hazardous } & Central & Farms & 1 & 4 \\
\hline & & & & Central & Supermarket & 1 & \\
\hline & & & & Central & Vendor & 2 & \\
\hline
\end{tabular}






Pesticide

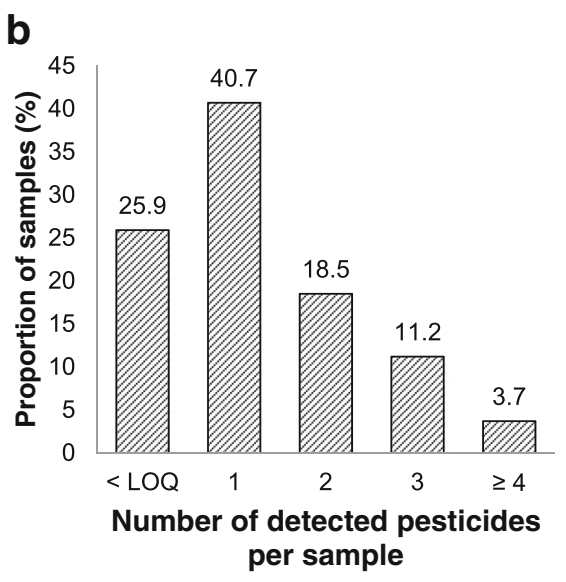

Fig. 3 Summary results showing proportion of (a) detections per pesticide and (b) samples with specific number of pesticides detected per sample
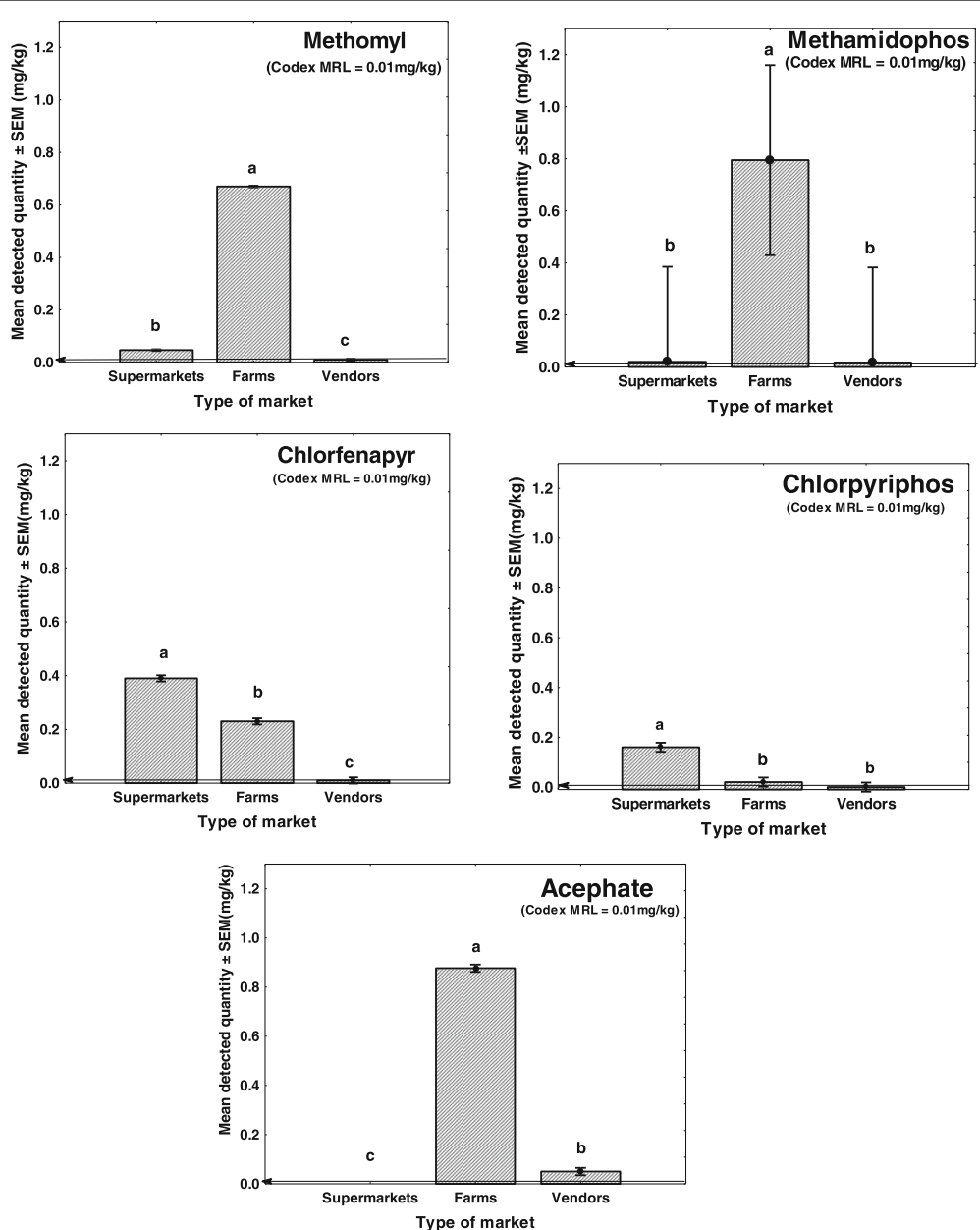

Fig. 4 The mean detected quantities for pesticides above the FAO/WHO Codex Alimentarius (MRL) thresholds for methomyl, chlorfenapyr, methamidophos, chlorpyriphos and acephate. The Codex Alimentarius MRL thresholds are indicated by the arrow. Data on MRL thresholds were derived from Codex Alimentarius online database (Codex Alimentarius, 2017) 
WHO Codex MRL of $0.01 \mathrm{mg} / \mathrm{kg}$ (see Fig. 4). For chlorfernapyr, mean detected residue quantities in samples from the supermarkets $(0.39 \mathrm{mg} / \mathrm{kg})$ were significantly higher $(p<0.001)$ than both farms and vendors. However, mean residue quantities in samples from the farms $(0.23 \mathrm{mg} / \mathrm{kg})$ were significantly higher $(p<0.001)$ than those from the vendors $(0.01 \mathrm{mg} / \mathrm{kg})$. Similar to methomyl, chlorfenapyr had residues exceeding the FAO/ WHO Codex MRLs in samples from both farms and supermarkets $(p<0.001)$ but not in samples from vendors (Fig. 4).

Methamidophos had a wide range of residue quantities detected especially in samples from the farms (0.04-2.9 $\mathrm{mg} / \mathrm{kg}$ ) with a mean of $0.8 \mathrm{mg} / \mathrm{kg}$ which was significantly higher $(p=0.005)$ than both supermarkets $(0.02 \mathrm{mg} / \mathrm{kg})$ and vendors $(0.018 \mathrm{mg} / \mathrm{kg})$. Residues from all the three types of markets exceeded the FAO/WHO Codex MRLs although at different magnitudes (see Fig. 4). Similar to chlorfenapyr, chlorpyriphos mean residues quantities were significantly higher $(p<0.001)$ in samples from the supermarkets $(0.16 \mathrm{mg} / \mathrm{kg})$ compared to farms and vendors both of which were not significantly different from each other. Both farms and supermarkets exceeded the Codex MRLs. As observed in the other two organophosphates (methamidophos and methomyl), acephate mean detected residue quantities were significantly higher $(p<0.001)$ on samples from the farms $(0.88 \mathrm{mg} /$ $\mathrm{kg}$ ) than both supermarkets and vendors. Supermarket residues $(0.05 \mathrm{mg} . \mathrm{kg})$ were however significantly higher $(p<0.001)$ than vendors (Fig. 4$)$.

Residues from both farms and supermarkets exceeded the FAO/WHO Codex MRLs by different number of times-as-great (magnitudes or folds). The number of times each pesticide exceeded the Codex MRL varied across the types of markets (Fig. 5). For methomyl, methamidophos and acephate, the mean quantity of detected residues were higher in samples from farms, exceeding the Codex MRL by 67, 80 and 87.7 times respectively (see Fig. 5). However, chlorpyriphos and chorfenapyr exceeded the thresholds more in supermarkets, 16 and 39-times respectively. Samples from vendors mostly did not exceed the Codex MRLs for all of the pesticide residues except acephate which exceeded 5-fold (Fig. 5). Using the potential daily vegetable consumption of $0.7 \mathrm{~g} /$ person/day, an average body weight of $60 \mathrm{~kg}$ (WHO/GEMS/FOODS) (2006), and the grand mean of detected amount $(\mathrm{mg} / \mathrm{kg}$ ) for each pesticide, we estimated the pesticide daily intake (ADI) and Acute Reference Doses (ARfD) (as in Alla et al. 2015) (Table 4). Both the mean detected quantity and the estimated per capita consumption/day were below the WHO ADI and ARfD for all pesticides (Table 4).

\section{Discussion}

Our study showed multiple and excessive pesticide residues on 'fresh' cabbage vegetable markets in Botswana; and to our knowledge, this is the first report to date, detailing such in an arid African context. We detected organophosphates, pyrethroids, carbamates, pyrroles, neonicotinoids and a diamide in $74.1 \%$ of the tested samples with $33.4 \%$ showing multiple pesticide residue detections per individual sample. These results resonate with $66.5 \%$ total detections and 35\% multi-pesticides detections observed in apples in Poland (Lazowicka 2015) and also concur with recent findings from Ghana (Amoah et al. 2006; Osei-Fosu et al. 2017), Zambia

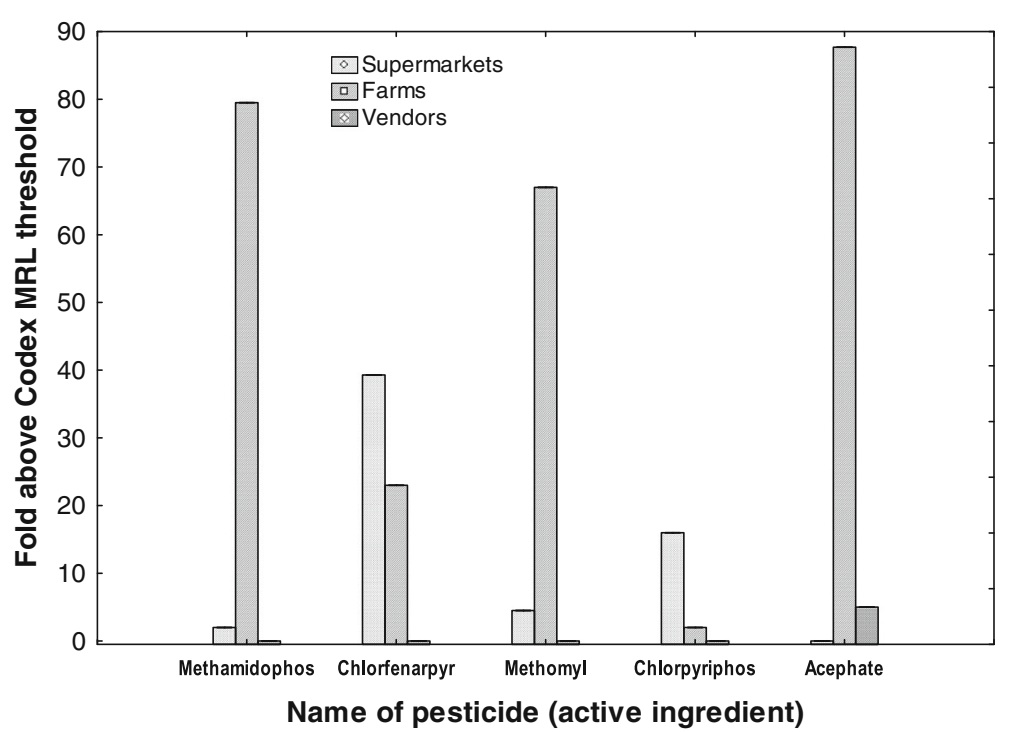

Fig. 5 Summary results showing the number of times (folds) each pesticide exceeded the Codex Alimentarius MRL threshold at each type of market. Data on MRL thresholds were derived from Codex Alimentarius online database (Codex Alimentarius, 2017) 
Table 4 An indication of the magnitude of exposure to selected detected hazardous pesticides based on the estimate of per capita consumption/day compared to WHO's Acceptable daily intake ADI and Acute reference dose (ARfD) limits. Data are based on recommended per capita consumption of $0.7 \mathrm{~g} /$ person/annum for leaf vegetable consumption in Africa (see WHO/GEMS/FOODS, 2006; Alla et al. 2015). Data on (ADI) and (ARfD) obtained from WHO online database (WHO, 2017)

\begin{tabular}{|c|c|c|c|c|c|c|}
\hline Active ingredient & $\begin{array}{l}\text { Range of detected } \\
\text { quantity }(\mathrm{mg} / \mathrm{kg})\end{array}$ & $\begin{array}{l}\text { Overall mean } \\
\text { detected quantity } \\
(\mathrm{mg} / \mathrm{kg})\end{array}$ & $\begin{array}{l}\text { Codex } \\
\text { Alimentarius } \\
\text { MRLs (mg/kg) }\end{array}$ & $\begin{array}{l}\text { aPercapita } \\
\text { consumption/day } \\
(\mathrm{mg} / \mathrm{kg})\end{array}$ & $\begin{array}{l}{ }^{\mathrm{b}} \text { Acceptable daily } \\
\text { intake (ADI) } \\
\text { (mg/kg bw/day) }\end{array}$ & $\begin{array}{l}{ }^{\mathrm{b}} \text { Acute reference } \\
\text { dose (ARfD) } \\
(\mathrm{mg} / \mathrm{kg} \mathrm{bw})\end{array}$ \\
\hline Acephate & $0.05-0.89$ & 0.60 & 0.01 & 0.0042 & 0.03 & 0.1 \\
\hline Chlorpyriphos & $0.02-0.16$ & 0.09 & 0.01 & 0.00063 & 0.01 & 0.1 \\
\hline Methamidophos & $0.02-2.90$ & 0.33 & 0.01 & 0.00231 & 0.004 & 0.01 \\
\hline Methomyl & $0.01-0.67$ & 0.19 & 0.01 & 0.00133 & 0.02 & 0.02 \\
\hline Chlorfenapyr & $0.01-0.39$ & 0.21 & 0.01 & 0.00147 & 0.03 & 0.03 \\
\hline
\end{tabular}

${ }^{\mathrm{a}}$ Based on recommended per capita consumption of $0.7 \mathrm{~g} /$ person/annum (WHO/GEMS/FOODS) (2006) for leaf vegetable consumption in Africa (see also Alla et al. 2015)

${ }^{b}$ Data on (ADI) and (ARfD) obtained from WHO online database based on $60 \mathrm{~kg}$ average body weight (bw) (WHO/GEMS/FOODS) (2006; WHO, 2017)

(Mwanja et al. 2017) and Kuwait (Jallow et al., 2017). Fifty percent of total pesticide detections were above the Codex Alimentarius MRLs permitted by law and these were dominated by organophosphates; classified as highly hazardous (Class 1B) (WHO, 2009). We document that farmgate sales were the major market source of high levels of residue contaminated vegetables compared to supermarkets and vendors. Although vendors and supermarkets got their vegetables from the farms, the protracted time lag between buying from the farm and selling to consumers may enable further degradation of the pesticide. The similarity in the types and quantities of detected pesticides in space confirmed the uniform rampant, uncontrolled and injudicious pesticide abuse behaviour in the African vegetable production systems, as previously reported by Machekano et al. (2017, 2019).

The multi-detectetion and dominance of organophosphates and carbamates at quantities above the Codex MRLs in our findings is a cause for concern. Organophoshates and cabarmates have high mammalian toxicity (WHO 2009) through the inhibition of Acetylcholine Esterase (AChE), an enzyme that catalyses the hydrolysis of Acetylcholine (Ach), an essential neurotransmitting agent in humans (Fukuto 1990; Rathnayake and Northrup 2016; Medscape 2017). Low AChE activity in the blood is used as a biomarker for body organophosphate accumulation (Repetto and Baliga 1996; Magauzi et al. 2011). Inhibition of (Ach) causes short (Anand et al. 2009) and long (Hung et al. 2015) term heart and respiratory functions (Fukuto 1990; Medscape 2017) as well as retarded cognitive development in children (Engel et al. 2011). However, for the African consumers, 'lack of knowledge' on pesticide residues on food, 'lack of consciousness' on the link between consumption and organophosphate poisoning, as well as other social ills mask the visibility of the chronic effects of pesticide residue exposure (Macharia et al. 2015).
Cypermethrin and fenvarelate detected here, are type II pyrethroids with extremely high toxicity (Bradberry et al. 2005; WHO 2005). Exposure of humans to pyrethroids has been reported to disrupt the endocrine system, e.g. through its estrogen mimicry affecting reproductive functions (reviewed in Bradberry et al. 2005). We also detected a neonicotinoid (imidacloprid) in our samples, human exposure to moderate or high doses has been observed to affect central nervous system function causing tremors, impaired pupillary function, hypothermia, drowsiness and dizziness (Wu et al. 2001; Sheets et al. 2015). Similarly, the pyroles, e.g. chlorfenapyr detected here, is highly toxic and environmentally persistent. In humans, it affects metabolism (Albers et al. 2006), e.g. causes loss of body fat, muscle wasting and bile retention. If unchecked, the bio-accumulation of these residues in human body due to continued and multiple (product) consumption may have deleterious effects on public health that may be difficult to trace back and link with pesticide exposure in the future (Albers et al. 2006).

Our results showed that residue levels in cabbage sampled from supermarkets were not significantly different from those sampled from farms. The high stock turnover, supported by frequent re-stocking and refrigerated storage facilities may explain this trend. Both the low temperature storage facilities and the frequent 'fresh' supplies from the farms, keep pesticide residues in supermarket produce higher compared to vendors. Conversely, vendors had the least quantities of detected pesticide residues and lowest total number of detections owing to their low stock turnover allowing for pesticide degradation over time (protracted marketing period). Furthermore, the vegetable produce is often exposed to the outside and sunny environment, which may facilitate faster dispersion and photo-degradation of chemicals. As a whole, this observation may point to the notion that 
"the 'fresher' the vegetables, the more contaminated they may, and vice-versa" as reinforced by the negative correlation observed between quantity of detected pesticides and length of time between delivery and sampling. This meant that the shorter the time lag between delivery and sampling, the higher the detected pesticide quantity. However, due to public quality demands and 'lack of knowledge', most consumers prefer the more contaminated 'fresh' farm or supermarket produce, while denigrating the supposedly stale but safer stocks from the vendors or often organically produced produce.

Our study is the first to compare vegetable pesticide residues across different domestic markets to unravel evidence of potential public health risks. Irrespective of the market source, Thompson et al. (2017) showed the occurrence of organochlorines in 13 African countries not only in vegetables but also in human breast milk and blood serum. This calls for an urgent need for intervention to prevent insurmountable pesticide related public health burdens on already resource constrained African governments. Higher residue contamination on samples from the farms may be because on-farm sales are made more immediate to spraying time, not allowing for pesticide degradation in time. It could also be due to high frequency of application or higher than recommended dosages (Ngowi et al. 2007; Williamson et al. 2008; Machekano et al. 2019) or a combination thereof. Moreover, high residues reported here, may also be due to the intentional or unintentional failure to adhere to recommended pesticide withdrawal periods (as in e.g. Williamson et al. 2008; Ngowi et al. 2007; Machekano et al. 2019) owing to lack of knowledge and market competition (Williamson et al. 2008; Machekano et al. 2019). Withdrawal periods for some of the pesticides detected here are high, e.g. 14 days for imidachloprid and 21 days for both methamidophos and chlorantraniliprole. However, Machekano et al. (2019) reported that $71.6 \%$ of farmers waited for a mean $\sim 10$ days, indiscriminate of the applied active ingredient. Moreover, some pesticides, e.g. fenvalerate, are not recommended for use in cruciferous crops. Nevertheless, these have been reported to be used indiscriminate of the crop type (see Machekano et al. 2019). Thus, existing regulations on pesticide misuse are not being observed, and this malpractice exposes the public to indirect 'pesticide' consumption through highly contaminated 'fresh' produce as evidenced by our results.

Although there was no violation of the toxicological reference values in the short (>ARfDs) and long terms (>ADIs), we nevertheless believe the WHO/GEMS/ FOODS (2006) leaf vegetable per capita consumption estimation of $0.7-\mathrm{g} / \mathrm{kg} /$ person in Africa used to calculate exposure risk in this study was an underestimation, cognizant of current consumption trends. There is need for recent per capita consumption data, on which to base calculations of 'realistic' toxicological reference values. This is a critical concern given the current high consumption of raw cabbage (salad) and/or as a cooked vegetable. Detection of multi-residues in one sample poses a high but yet neglected risk of bio-accumulation, bio-reaction, high human-pesticide burden and bio-magnification (Repetto and Baliga 1996; Boobies et al., 2008; Alla et al. 2015) with unknown human health consequences (Alla et al. 2015). Ito et al. (1996) reported an increase in the number and size of liver lesions in rats exposed to diverse rather than single pesticide(s). Similarly, occupational multiple pesticide exposure has been reported to cause short term (e.g. headaches, nausea, abdominal pains) to long term cancers, reproductive, nervous and endocrine system disruptions (Macharia et al. 2011; reviewed in Donkor et al. 2016). In African systems, there is scarcity of laboratory equipment and skills to detect pesticides in food let alone diagnosing patient symptoms to multi-pesticide residue exposure (Boobis et al. 2008).

To protect public health, market regulation of pesticide residues may be the only viable solution currently. This can be achieved through policy regulatory frameworks and consumer empowerment to induce market rejection and enforce farmers' behavioural change. Agrochemicals Regulation Acts e.g. Botswana, has stringent regulations on proper handling of pesticides, human and environmental protection. However, we feel that the weaknesses may be in (1) the inability by the governments to monitor farmers' activities and (2) the penalty for breaking the regulations is not prohibitive enough to enforce compliance. These challenges need to be addressed to comply with regional efforts, e.g. the recently formed Southern African Pesticide Regulators Forum (SAPReF) under Southern African Development Community (SADC) may be the key regional coordinator in regional policy harmonization, to improve the management, movement and use of pesticides. Promotion and funding of safer alternatives to pesticides such as Integrated Pest Management (IPM) can be advocated through such regional bodies to increase impact and tighten regional policies on pesticide risk management and risk reduction. Furthermore, pesticide half-life studies for compounds detected here need further investigation under Botswana climatic conditions, and explore the pesticide degradation period as a possible tool to ensure safe pesticide levels in marketed vegetable products (as in e.g. Donkor et al. 2016). Based on the results reported here, long term epidemiological studies may be needed to quantify the public health risk by ascertaining the degree of correlation and association between cumulative pesticide dietary exposure and chronic ill-health occurrences both in space and time. 


\section{Conclusion}

Multiple and excessive pesticide residues were present in consumer-ready cabbages across the three common markets in Botswana. Although with caveats, this scenario may be the same across other African vegetable value chain systems. We recorded the most toxic pesticide residues e.g. organophosphates and carbamates, occuring in quantities higher than the Codex MRLs. These results mean that the public are exposed and highly vulnerable to health risks associated with pesticide toxicity. Farmgate-sold produce had higher quantities of pesticide residues compared to supermarkets and vendors. To safeguard public health to pesticide exposure, we recommend investment in initiatives that improve small scale farmers' pesticide use behaviour and control pesticide misuse. The diverse and multi-detected above threshold pesticide residues reported here are also a cause for concern. We recommend that policymakers and other stakeholders alike, put in place stringent monitoring, regulating and enforcing frameworks on existing laws for good pesticide use practices by farmers. This may include (1) enforcing withdrawal periods (2) enforcing stricter misconduct penalties, (3) developing rapid pesticide residue testing kits across the value chain, (4) promoting awareness and funding sustainable bio-rational pest management methods e.g. biological control and (5) developing regulation and certification systems for fresh produce marketing.

\section{Additional file}

Additional file 1: Table S1. Validation performance parameters for the detected compounds using LC-MS/MS performed with cabbage sample matrices fortified at various concentrations. Table S2. Validation performance parameters for the detected compounds using GC-MS performed with cabbage sample matrices fortified at various concentrations. (DOCX $23 \mathrm{~kb})$

\section{Abbreviations}

ADI: Acceptable Daily Intake; ARfD: Acute Reference Dose; FAO: Food and Agriculture Organization; LOQ: Limit of Quantitation; MRLs: Maximum Residue Limits; SABS: South Africa Bureau of Standards; WHO: World Health Organization

\section{Acknowledgements}

We acknowledge the Botswana International University of Science and Technology research grant and the DAAD-NAPRECA In-Region scholarship for funding. We also acknowledge the Department of Crop Protection (Ministry of Agriculture, Republic of Botswana) for assistance in field sampling. We are grateful to the farmers, vendors and supermarkets who participated in this study.

\section{Funding}

The project was funded through Botswana International University of Science and Technology (BIUST) Research Office grant and the German Academic Exchange Service or Deutscher Akademischer Austauschdienst Natural Products Research Network for East and Central Africa (DAADNAPRECA) in-region scholarship to the first author.

\section{Availability of data and materials}

Collected and analysed data are available upon request from the corresponding author.

\section{Authors' contributions}

$\mathrm{HM}$ and $\mathrm{CN}$ contributed to project conceptualization and WM contributed the methodology; CN contributed to funding acquisition, project administration, and resources. $\mathrm{CN}$ and BMM contributed to supervision; $\mathrm{HM}, \mathrm{CN}$ and WM contributed to investigation and writing of the original draft, data curation, validation, formal analysis and writing. HM, CN, BMM and WM contributed to review and editing. All authors read and approved the final manuscript.

\section{Authors' information}

HM: PhD, Botswana International University of Science and Technology (BIUST).

BMM: PhD, and Professor, University of Zimbabwe.

WM: PhD, and Professor, BIUST.

CN: PhD and Senior Lecturer, BIUST.

\section{Competing interests}

The authors declare that they have no competing interests.

\section{Publisher's Note}

Springer Nature remains neutral with regard to jurisdictional claims in published maps and institutional affiliations.

\section{Author details}

${ }^{1}$ Department of Biological Sciences and Biotechnology, Botswana International University of Science and Technology, Private Bag 16, Palapye, Botswana. ${ }^{2}$ Department of Soil Science and Agricultural Engineering, Faculty of Agriculture, University of Zimbabwe, P. O Box MP167, Mt Pleasant, Harare, Zimbabwe. ${ }^{3}$ Department of Chemical and Forensic Sciences, Botswana International University of Science and Technology, Private Bag 16, Palapye, Botswana.

Received: 24 September 2018 Accepted: 22 January 2019

Published online: 02 February 2019

\section{References}

Albers PH, Klein PN, Green DE, Melancon MJ, Brian P, Bradley BP, Noguchi G. Chlorfenapyr and mallard ducks: overview, study design, macroscopic effects, and analytical chemistry. Environ Toxicol Chem. 2006;25:438-45.

Alla SAG, Loutfy NM, Shendy AM, Ahmed MT. Hazard index, a tool for a long term risk assessment of pesticide residues in some commodities, a pilot study. Regul Toxicol Pharmacol. 2015:73:985-91.

Amoah P, Drechsel P, Abaidoo RC, Ntow WJ. Pesticide and pathogen contamination of vegetables in Ghana's urban markets. Arch Environl Contam Toxicol. 2006;50:1-6.

Anand S, Singh S, Nahar-Saikia U, Bhalla A, Paul-Sharma Y, Singh D. Cardiac abnormalities in acute organophosphate poisoning. Clin Toxicol (Phila). 2009; 47:230-5.

Anastasiades M, Stajnbaher D, Schenk FJ, Lehotay S. Fast and easy multiresidue method employing acetonitrile extraction/partitioning and "dispersive phase solid-phase extraction for the determination of pesticide residues in produce". J AOAC Int. 2003;86:412-31.

Banti M, Shukla G, Taneja A. Contamination levels of organochlorine pesticides and farmers' knowledge, perceptions and practices in rural India: a case study. Bull Environ Contam Toxicol. 2004;73:787-93.

Bempah CK, Donkor A, Yeboah PO, Dubey B, Osei-Fosu P. A preliminary assessment of consumer's exposure to organochlorine pesticides in fruits and vegetables and the potential health risk in Accra Metropolis, Ghana. Food Chem. 2011;128:1058-1065.

Boobis AR, Bernadette C, Banasiak U, Hamey PY, Sebestyen I, Moretto A. Cummulative risk assessment of pesticide residues in food. Toxicol Lett. 2008; 180:137-50.

Bradberry SM, Cage SA, Proudfoot AT, Vale JA. Poisoning due to pyrethroids. Toxicol Rev. 2005;24:93-106.

Codex Alimentarius (2017) International Food Standards. Available at: http:// www.fao.org/fao-who-codexalimentarius/codex-texts/maximum-residuelimits/jp/. Accessed 10 November, 2017. 
Damallas CA, Eleftherohorinos IG. Pesticide exposure, safety issues and risk assessment indicators. Int J Environ Res Public Health. 2011:8:1402-19.

Donkor A, Osei-Fosu P, Dubey B, Kingsford-Adaboh R, Ziwu C, Asante I. Pesticide residues in fruits and vegetables in Ghana: a review. Environ Sci Pollut Res. 2016;23:18966-87.

Engel SM, Wetmur J, Chen J, Zhu C, Barr DB, Canfield RL, Wolff MS. Prenatal exposure to organophosphates, Paraoxonase 1, and cognitive development in childhood. Environ Health Perspect. 2011;119:1182-8.

Fernandez-Alba AF (2005) Chromatographic-mass spectrometric food analysis for trace determination of pesticide residues. eBook Vol. 43. ISBN: 9780080454405, Elsevier Armsterdam, The Nertherlands.

Food and Agriculture Organisation (FAO). FAOSTAT. Rome. Italy: FAO; 2004. Available at:http://www.fao.org/statistics/databases/en/.

Food and Agriculture Organisation (FAO). How to feed the world in 2050. Rome, Italy: FAO; 2009.

Fukuto RT. Mechanisms of action of organophosphorus and cabarmate insecticides. Environ Health Perspect. 1990;87:245-54.

Fulco CE, Liverman CT, Sox HC. Effects of long-term exposure to organophosphate pesticides in humans. Gulf war and health: volume 1. Depleted uranium, sarin, Pyridostigmine bromide, vaccines. In: Institute of Medicine (US) committee on health effects associated with exposures during the Gulf war. Washington USA: National Academic Press; 2000.

Hinson AV, Hounfipko H, Dossou F, Pazou EY, Aguemon B, Lawin H, Koudafoke A, Fabien G, Houngbegnon P, Fayomi B. Effect of using pesticide, on erythrocyte acetylcholinesterase level and risk factors of poisoning among cotton workers in Benin. Int Res J Public Environ Health. 2017;4:55-63.

Hung DZ, Yang HJ, Lee YF, Lin CL, Chang SY, Sung FC, Tai SCW. The long-term effects of organophosphates poisoning as a risk factor of CVDs: a Nationwide population-based cohort study. A Nationwide population-based cohort study. PLoS One. 2015;10(9):e0137632. https://doi.org/10.1371/journal.pone. 0137632.

IPCC. Climate change 2014: synthesis report. Contribution of working groups I, II and III to the fifth assessment report of the intergovernmental panel on climate change [Core writing team, R.K. Pachauri and L.a. Meyer (eds.)]. Geneva, Switzerland: IPCC; 2014. p. 151.

Ito N, Hagiwara A, Tamano S, Futacuchi M, Imaida K, Shirai T. Effects of pesticide mixtures at the acceptable daily intake levels on rat carcinogenesis. Food Chem Toxicol. 1996;34:1091-6.

Jallow MFA, Awadh DC, Albaho MS, Devi VY, Ahmad N. Monitoring of pesticide residues in commonly used fruits and vegetables in Kuwait. Int J Environ Res Public Health. 2017;14:833. https://doi.org/10.3390/ijerph14080833.

Lazowicka B. Health risk for children and adults consuming apples with pesticide residues. Sci The Total Environ. 2015;502:184-98.

Leroy JL, Ruel M, Frongillo EA, Harris J, Ballard TJ. Measuring the food access dimension of food security: a critical review and mapping of indicators. Food Nutr Bull. 2015;36:167-95. https://doi.org/10.1177/0379572115587274.

Macharia I (2015) Pesticides and health in vegetable production in Kenya. BioMed Res Int. https://doi.org/10.1155/2015/241516.

Macharia I, Mithöfer D, Waibel H. Indirect and External Costs of Pesticide Use in the Vegtable Sub-sector in Kenya. CABI. 2011; ebook: 227-232.

Machekano H, Mvumi BM, Nyamukondiwa C. Diamondback moth, Plutella xylostella (L.) in southern Africa: research trends, challenges and insights on sustainable management options. Sustain. 2017;9:91. https://doi.org/10.3390/ su9020091.

Machekano H, Mvumi BM, Nyamukondiwa C. Plutella xylostella: pest status, control practices, perceptions and knowledge on existing and alternative management options in arid small-scale farming environments. Int J Pest Manag Sci. 2019. https://doi.org/10.1080/09670874.2018.1552380.

Madisa ME, Assefa Y, Obopile M. Crop diversity, extension services and marketing outlets of vegetables in Botswana. Egyptian Acad J Biol Sci. 2010;1:13-22.

Magauzi R, Mabaera B, Rusakaniko S, Chimusoro A, Ndlovu N, Tshimanga M, Shambira G, Chadambuka A, Gombe N. Health effects of agrochemicals among farm workers in commercial farms of Kwekwe district, Zimbabwe. Pan-Afr Med J. 2011;9:26. Available at: http://www.pubmedcentral.nih.gov/ articlerender.fcgi?artid=3215548.

Mazhawidza E, Mvumi BM. Field evaluation of aqueous indigenous plant extracts against the diamondback moth, Plutella xylostella $\mathrm{L}$. and the rape aphid, Brevicoryne brassicae L. in brassica production. Ind Crops \& Prod. 2017;110:36-44.

Mebdoua S, Lazali M, Aunane SD, Tellah S, Nabi F, Ounane G. Evaluation of pesticide residues in fruits and vegetables from Algeria. Food Addit Contam B. $2017 ; 10: 91-8$.
Medscape (2017) Organophosphate toxicity clinical presentation. https:// emedicine.medscape.com/article/167726-clinical. Accessed 23 Jan 2019.

Mostafalou S, Abdollahi M. Pesticides and human chronic diseases: evidences, mechanisms, and perspectives. Toxicol Appl Pharmacol. 2013;268:157-77.

Mwanja M, Jacobs C, Mbewe AR, Munyinda SN. Assessment of pesticide residue levels among locally produced fruits and vegetables in Monze District, Zambia. Int J Food Contam. 2017;4:11. https://doi.org/10.1186/s40550-017-0056-8.

Newton AC, Johnson SN, Gregory PJ. Implications of climate change for diseases, crop yields and food security. Euphytica. 2011;179:3-18.

Ngowi AVF, Mbise TJ, ljani ASM, London L, Ajayi OC. Smallholder vegetable farmers in Northern Tanzania: Pesticides use practices, perceptions, cost and health effects. Crop Prot. 2007; 26:1617-1624.

Nougadère A, Sirot V, Kadar A, Fastier A, Truchot E, Vergnet C, Homet F, Bayle J, Gros P, Leblanc JC. Total diet study on pesticide residues in France: levels in food as consumed and chronic dietary risk to consumers. Environ Int. 2012 ; 45:135-50.

Osei-Fosu P, Donkor A, Ziwu C, Dubey B, Kingsford-Adaboh R, Asante I, Stephen Nyarko S, Tawiah R, Nazzah N. Surveillance of pesticide residues in fruits and vegetables from Accra Metropolis markets, Ghana, 2010-2012: a case study in sub-Saharan Africa. Environ Sci Pollut Res. 2017;24:17187-205.

Rathnayake LK, Nortrup SH. Structure and mode of action of organophosphate pesticides: a computational study. Theor Chem. 2016;1088:9-23.

Repetto R, Baliga SS. Pesticides and the immune system: the public health risks; world resources institute: Washington, DC. In: USA; 1996.

Semple S. Assessing occupational and environmental exposure. Occup Med. 2005;55:419-24.

Sheets LP, Li AA, Minnema DJ, Collier RH, Creek MR, Peffer RC. A critical review of neonicotinoid insecticides for developmental neurotoxicity. Crit Rev Toxicol. 2015;46:153-90.

Szpyrka E, Kurdziel A, Matyasek A, Podbielska M, Rupar J, Slowik-Borowiec M. Evaluation of pesticide residues in fruits and vegetables from the region of south east Polland. Food Control. 2015;48:137-42.

Thompson LA, Darwish WS, Ikenaka Y, Nakayama SMM, Mizukawa H, Ishizuka M. Organochlorine pesticide contamination of foods in Africa: incidence and public health significance. J Vet Med Sci. 2017;79:751-64.

World Health Organization (WHO). Safety of Pyrethroids for public health use. In: WHO/CDS/WHOPES/GCDPP/2005 and WHO/PCS/RA/2005; 2005.

World Health Organization (WHO). WHO recommended classification of pesticides by Hazard and guidelines to classification 2009. In: World Health Organization; 2009.

World Health Organization Global Environment Monitoring System/Food Contamination Monitoring and Assessment Programme (WHO/GEMS/ FOODS) GEMS/Food Regional Diets (Regional Per Capita Consumption of Raw and Semi-Processed Agricultural Commodities). 2006.https://www.who. int/foodsafety/publications/chemical-risks/en/.

Wu IW, Lin JL, Cheng ET. Acute poisoning with the neonicotinoid insecticide Imidacloprid in N-methyl Pyrrolidone. J Toxicol Clin Toxicol. 2001;39:617-21.

\section{Ready to submit your research? Choose BMC and benefit from:}

- fast, convenient online submission

- thorough peer review by experienced researchers in your field

- rapid publication on acceptance

- support for research data, including large and complex data types

- gold Open Access which fosters wider collaboration and increased citations

- maximum visibility for your research: over $100 \mathrm{M}$ website views per year

At BMC, research is always in progress.

Learn more biomedcentral.com/submissions 